\title{
Dengue Related Deaths at Ibn-Sina Hospital- Al-Mukalla: Causes and Alarming Signals
}

\author{
Ahmed Mubarak daakeek*, Husain S. Alghasali, Abdulrahim A. Bahashwan \\ Department of Medical, Faculty of Medicine and Health Sciences, Hadhramout University, Yemen
}

*Corresponding author: Ahmed Mubarak daakeek, Department of Medical, Faculty of Medicine and Health Sciences, Hadhramout University, Yemen, Tel: +967777785980; E-mail: daakeek@gmail.com

Received date: October 11, 2017; Accepted date: October 30, 2017; Published date: November 01, 2017

Copyright: (C) 2017 Dakeek AM, et al. This is an open-access article distributed under the terms of the Creative Commons Attribution License, which permits unrestricted use, distribution, and reproduction in any medium, provided the original author and source are credited.

Citation: Dakeek AM, Alghasali HS, Bahashwan AA. Dengue Related Deaths at Ibn-Sina Hospital- Al-Mukalla: Causes and Alarming Signals. J Infec Dis Treat. 2017, Vol.3 No.2:10.

\section{Abstract}

Objective: To identify the causes and alarming signal of dengue-related deaths during the 2015-2016 dengue outbreak in Muklalla-Yemen.

Settings and design: A prospective descriptive study was conducted in Ib-Sina Hospital-Mukalla-Yemen.

Method: Deaths due to dengue fever were reviewed from hospital records. Demographic details, clinical features, laboratory findings, and the treatment charts of death cases were reviewed and documented. Comorbidities were also listed, and causes and warning signs were evaluated and highlighted. Data were analyzed using SPSS statistical software version 21.

Results/Findings: Out of $\mathbf{4 2 4}$ dengue fever (DF) patients who admitted during outbreak period, 18 dengue-related deaths were reported (4.25\%); 10 (55.6\%) were male, and $8(44.4 \%)$ were female. The mean age was 28.11 years. Most cases from Fuwwah and Mukalla city (50\%). The diagnosis at the time of presentation was severe dengue (SD) in all patients. Three (15.9\%) patients had comorbidity. Dengue shock, fulminant hepatitis, encephalitis and acute respiratory distress syndrome were the most common causes of death. Nausea, vomiting, abdominal pain, hypotension, altered mental status, convulsion, leukocytosis, rapid fall in platelet and elevated liver enzymes were alarming signals of fatal dengue.

Conclusion: Dengue-related deaths often occurs in young adult patients and shock state was the most common cause principally in females. Among died patients, raised hematocrit were not useful in identifying patients with plasma leakage. The causes and alarm signals for death were somewhat similar to other regional studies mostly in Asian countries.
Keywords: Dengue fever; Severe dengue fever; Mukalla; Yemen

\section{Introduction}

Dengue is a systemic viral infection transmitted between humans by Aedes mosquitoes. For some patients, dengue is a life-threatening illness. A recent study estimated the global burden of dengue to be 390 million infections per year, of which 96 million manifest apparently (any level of disease severity) [1]. Dengue virus infection in humans is often unapparent, but can lead to a wide range of clinical manifestations, from mild fever to potentially fatal dengue shock syndrome [2]. The lifelong immunity developed after infection with one of the four virus types is type-specific.

The disease is characterized by the presence of fever, frontal headache, myalgia, arthralgia and cutaneous rash, usually selflimited to one week. Mild or a symptomatic infection are often associated with primary infections. Severe forms are characterized by the presence of hemorrhages, hypotension, thrombocytopenia and plasma leakage, also accompanied by neurological alterations [3], conditions that could eventually lead to shock and multi-organ failure and that could worsen in the presence of comorbidities.

Majority of patients with dengue fever (DF) recover without complications. The mortality is $1-5 \%$ without treatment [3] and $<1 \%$ if adequate treatment is provided. However, severe disease was reported to carry a mortality of $26 \%$ [4]. Predictors of mortality include shock [5], severe hepatitis (alanine transaminase (ALT) $>300 \mathrm{IU} / \mathrm{I}$ ), altered mental status, and a history of bleeding at admission [6]. Other predictors include atypical presentations, comorbidities, secondary bacterial infection and abnormal serum markers at presentation [7].

There are no licensed vaccines or antiviral drugs against the disease, although some potential solutions are currently being studied [8]. Early appropriate treatment, vector control, and educational program are the only current methods to reduce mortality and global disease burden $[2,9]$. Therefore, the 
World Health Organization (WHO) encourages research based around markers of severity to develop new tools and methods that can reduce the healthcare burden of dengue infection in endemic countries.

Dengue fever has emerged as one of the major public health problems in hadhramout in recent years. The reported dengue outbreak in Hadramout indicated the potential threat of dengue as public health issue [10]. DENV-3 was confirmed to be the cause of an outbreak of DHF in Al-Mukalla in 2010 [11].

In the end of 2015, Mukalla, the capital of Hadhramout governarate -Yemen, faced an unprecedented outbreak of dengue. During this largest epidemic in Mukalla city history, thousands became infected, hundreds were admitted to the hospitals, and some died. In this period Mukalla city and coast of hadhramout under authority of Al-Qaeda organization and the country under political and military crises, for that reasons there is a lack of health facilities helping in diagnosis and dealing with dengue cases.

In this study, we describe the clinical and laboratory characteristics of fatal cases of DF admitted to Ibn-sina Hospital- Mukalla and the most symptoms and signs predicted to severe DF and death.

\section{Materials and Methods}

\section{Study design and data collection}

The study was conducted at Ibn-Sina Hospital- Mukalla, a tertiary care teaching facility. Hospital records were reviewed for all reported cases of dengue-related death and deaths among patients hospitalized with a diagnosis of dengue fever (DF) between the first week of November 2015 and last week of February 2016.

To be included, deaths had to be declared as dengue-related deaths on the basis of clinical features and laboratory profile.
Patients who fulfilled the WHO case definition proposed by Tropical Disease Research (TDR) [2] with supportive evidence of a dengue virus (DENV) infection by rapid test for dengue antibodies.

Demographic details, clinical features, laboratory findings, and the treatment charts of death cases were reviewed and documented on a standardized form. Comorbidities were listed. The demographic profile of all admitted patients was also reviewed.

\section{Case definitions}

Case definitions based on the classification of Dengue fever which was proposed by Tropical Disease Research (TDR) and published in the WHO TDR 2009 dengue guidelines [2] (Table 1).

\section{Laboratory diagnosis}

Serum samples collected more than 5 days after the onset of fever were tested for rapid anti-dengue IgM and IgG antibodies and in early cases ( $<3$ days) for rapid Nonstructural protein 1 (NSI) antigen test. Elisa test for dengue antibodies was used only to prove dengue epidemic by health authorities (due to limited resources). RT-PCR was not performed on our cases due to unavailability.

\section{Data analysis}

Data were analyzed using SPSS statistical software version 21. Frequencies of different categorical variables were calculated. The median and range were calculated for continuous variables. Patient characteristics were compared using the Chi-square test or Fisher's exact test for categorical variables. The Mann-Whitney test was used for continuous variables. A 1-sided $p<0.05$ was considered to be statistically significant at the $95 \%$ confidence level.

Table 1 Classification of Dengue fever proposed by Tropical Disease Research (TDR).

\begin{tabular}{|c|c|}
\hline Dengue type & Criteria \\
\hline \multicolumn{2}{|l|}{ Dengue \pm warning signs } \\
\hline 1. Probable dengue & $\begin{array}{l}\text { Live in /travel to dengue endemic area. } \\
\text { Fever and } 2 \text { of the following criteria } \\
\text { - } \quad \text { Nausea, vomiting } \\
\text { - } \quad \text { Rash } \\
\text { - } \quad \text { Aches and pains } \\
\text { - } \quad \text { Tourniquet test positive } \\
\text { - } \quad \text { Leukopenia }\end{array}$ \\
\hline 2. Dengue with warning signs & $\begin{array}{ll}\text { - } & \text { Abdominal pain and tenderness } \\
\text { - } & \text { Persistent vomiting } \\
\text { - } & \text { Clinical fluid accumulation } \\
\text { - } & \text { Mucosal bleed } \\
\text { - } & \text { Lethargy, restlessness } \\
\text { - } & \text { Liver enlargement }>2 \mathrm{~cm} \\
\text { - } & \text { Laboratory: increase in HCT concurrent with rapid decrease in platelet count }\end{array}$ \\
\hline 3. Severe dengue fever & 1. Severe plasma leakage leading to: \\
\hline
\end{tabular}




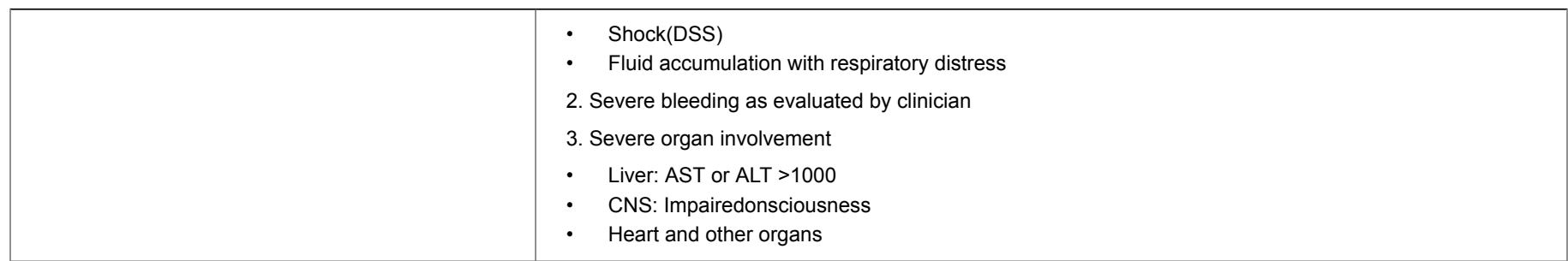

\section{Results}

A total of 424 patients with dengue were hospitalized; 272 (64.15\%) were males, 152 (35.85\%) were females. The median age was 26 years (range 17-50 y). Of them, eighteen death cases were reported, resulting in a mortality rate of approximately $4.25 \%$ of all cases. All of these patients were older than 15 years (mean=28.11 y). There were 10 (55.6\%) males and $8(44.4 \%)$ females with $M$ : $F$ raio (1.25:1). Females were approximately equal to males (median age of females was 25 years, range $17-50$ years versus median age of males was 26 years, range 19-46 years). Most of dead cases were from Fuwwah and Al- Mukalla city (Figure 1).

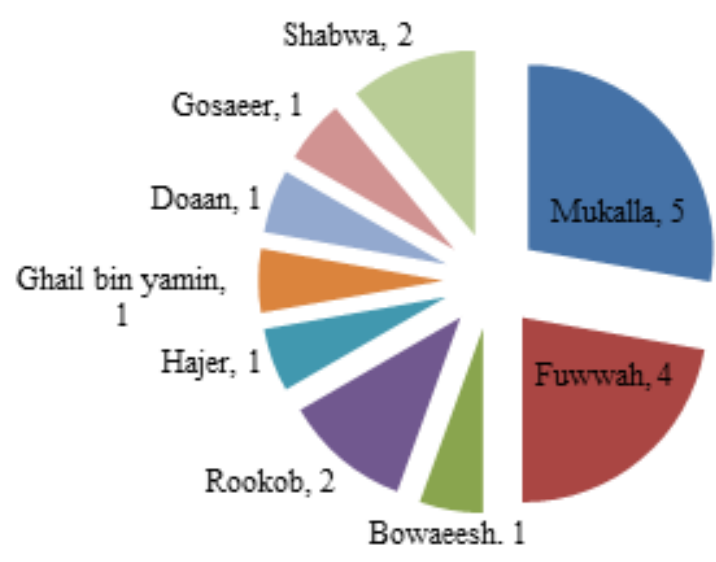

Figure 1 Geographical distribution of fatal dengue case.

\section{Clinical features}

The majority of patients (70\%) had become afebrile at the time of admission. The most common presenting complaints were arthralgia and myalgia (94.4\%) and headache $(88.9 \%)$, while the common warning symptoms were persisting vomiting $(66.7 \%)$, abdominal pain and tenderness $(61.1 \%)$ bleeding (44.4\%) and altered mental status and convulsion (38.9\%). The common presenting signs were shock BP $(\leq 90$ $\mathrm{mm} / \mathrm{Hg}$ ) and tachycardia ( $\geq 100)(44.4 \%)$ (Table 2 ).

The most common diagnosis at the time of presentation was severe dengue syndrome. There was no statistically significant difference between male and female patients in terms of duration of illness and duration of hospital stay.

Table 2 Clinical presentations of fatal dengue cases.

\begin{tabular}{|c|c|c|c|}
\hline Clinical features & M & F & $\begin{array}{c}\text { Total number of } \\
\text { cases (\%) }\end{array}$ \\
\hline Arthralgia and Myalgia & 10 & 7 & $17(94.4)$ \\
\hline Headache & 9 & 7 & $16(88.9)$ \\
\hline Persisting Vomiting & 6 & 6 & $12(63.2)$ \\
\hline Ret orbital pain & 8 & 3 & $11(61.1)$ \\
\hline Abdominal pain and & 7 & 4 & $11(61.1)$ \\
\hline tenderness & 4 & 4 & $8(44.4)$ \\
\hline Bleeding & 3 & 5 & $8(44.4)$ \\
\hline Hypotension and Shock $\leq 90$ & 5 & 3 & $8(44.4)$ \\
\hline Tachycardia $\geq 100$ & 5 & 2 & $7(38.9)$ \\
\hline Convulsions & 5 & 2 & $7(38.9)$ \\
\hline Ascites and pleural effusion & 3 & 0 & $3(16.7)$ \\
\hline Pulse pressure $\leq 20$ & 1 & 2 & $3(16.7)$ \\
\hline
\end{tabular}

\section{Laboratory findings}

Laboratory findings of these patients are depicted in Table 3. Leukocytosis (Total leukocyte count $>10,000 / \mathrm{mm}^{3}$ ) was seen in $5(28 \%)$ patients at admission. The cause of leukocytosis was found to be encephalitis in 3 patients, reactive due to bleeding in two cases. At presentation, both females and males had significantly normal to lower hematocrit $(\mathrm{Htc})$ (median range: $35(31-44)$ vs $41(23-45))$. The increase in the aspartate transaminase (AST) level was higher than that of alanine transaminase (ALT) (median range: $80 \mathrm{IU} / \mathrm{L}$ (40-5300 IU/L) vs $60 \mathrm{IU} / \mathrm{L}(40-4440 \mathrm{IU} / \mathrm{L}))$. IgM and IgG rapid anti-dengue antibodies was positive in 9 patients.

\section{Cause of death}

The cause of death was multifactorial in most of cases, arranged from dengue shock, fulminant hepatitis with hepatic encephalopathy, encephalitis, intracerebral hemorrhage, acute respiratory distress syndrome (ARDS), renal failure and Pulmonary edema due to over hydration. In females, the most cause of death was Dengue shock alone (5 cases) or with encephalitis ( 2 cases) and hepatic encephalopathy (I case). Three patients also had previous illness of Diabetes, chronic 
liver disease and Bronchial asthma and participating death due to diabetic ketoacidosis with renal failure, hepatic encephalopathy and ARDS respectively (Figure 2).

Table 3 Para clinical finding in fatal dengue cases.

\begin{tabular}{|l|r|r|l|}
\hline Investigation & M & F & Total and \% \\
\hline Platelet $<100000$ & 8 & 8 & $16(88.9)$ \\
\hline Total leukocyte count $<4000$ & 6 & 4 & $10(55.6)$ \\
\hline Total leukocyte count $>10000$ & 2 & 3 & $5(27.78)$ \\
\hline Albumin $<3.5$ & 8 & 6 & $14(77.8)$ \\
\hline Htc $>20 \%$ elevation & 0 & 0 & $0(0)$ \\
\hline PTT $>35$ & 2 & 2 & $4(22.22)$ \\
\hline PT $>15$ & 1 & 1 & $2(11.12)$ \\
\hline AST $>25$ & 2 & 1 & $3(16.7)$ \\
\hline ALT $>25$ & 1 & 0 & $1(5.6)$ \\
\hline Bilirubin $>1.5$ & 1 & 1 & $2(11.12)$ \\
\hline
\end{tabular}

A comparison of early (within 24 hours of presentation) versus late (more than 24 hours after presentation) deaths revealed that cases of early death were significantly equal in age, /sex, and comorbidities, and other finding (Table 4).

A three (15.9\%) patients had at least 1 comorbidity. The number of comorbidities was 1 in 2 patients (5.3\%), and 2 in one patient $(10.6 \%)$. The duration of hospital stay was variable: mean $=70$ hours, range $=1-312$ hours.

Two (11.12\%) patients received more than 4 platelet transfusions; one (5.6\%) patient received a blood transfusion. Transfusions did not produce sustained improvements in the coagulation status and has no direct relation to deaths in the study.

DSS: Dengue Shock Syndrome, ARDS: Acute Respiratory Distress Syndrome, H: hepatic, P: pulmonary, RF: Renal Failure, $\mathrm{ICH}$ : Intracranial Hemorrhage.

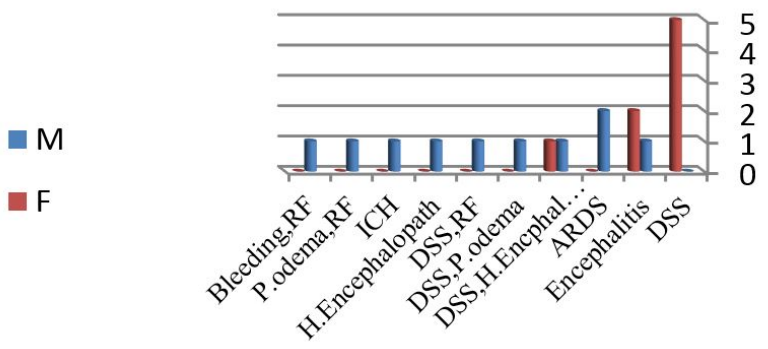

Figure 2 Causes of fatal dengue cases.

Table 4 Comparison of the clinical and laboratory profiles of early versus late deaths.

\begin{tabular}{|c|c|c|c|}
\hline $\begin{array}{l}\text { p- } \\
\text { value }\end{array}$ & Late deaths & $\begin{array}{l}\text { Early } \\
\text { deaths }\end{array}$ & Character \\
\hline 0.64 & $9(50 \%)$ & $9(50 \%)$ & $\mathrm{n}$ and $\%$ \\
\hline 0.32 & $30(19-40)$ & $27.2(17-50)$ & Age, y \\
\hline 0.64 & 0.084028 & $0.8: 1$ & Sex \\
\hline 1 & $5(55.6 \%)$ & $6(66.7 \%)$ & $\begin{array}{l}\text { Abdominal pain and } \\
\text { tenderness }\end{array}$ \\
\hline 0.62 & $7(77.8 \%)$ & $5(55.6 \%)$ & Persisting Vomiting \\
\hline 1 & $4(44.4 \%)$ & $3(33.3 \%)$ & Alter consciousness \\
\hline 0.86 & $4(44.4 \%)$ & $4(44.4 \%)$ & Bleeding \\
\hline 1 & $2(22.2 \%)$ & $1(11.1 \%)$ & Plasma leakage \\
\hline 0.21 & $110(70-140)$ & $80(0-130)$ & Systolic Bp mmHg \\
\hline 0.39 & $70(50-90)$ & $50(0-80)$ & Diastolic BpmmHg \\
\hline 0.44 & $40(20-50)$ & $40(0-60)$ & Pulse pressure $\mathrm{mmHg}$ \\
\hline 0.38 & $0(0-2)$ & $0(0-1)$ & Comorbidities \\
\hline 0.58 & $40(28-43)$ & $37(0-45)$ & Htc at presentation (\%) \\
\hline 0.38 & $\begin{array}{l}3500(1034-500 \\
0)\end{array}$ & $\begin{array}{l}3700(0-1800 \\
0)\end{array}$ & $\begin{array}{l}\text { TLC at presentation (per } \\
\mathrm{mm}^{3} \text { ) }\end{array}$ \\
\hline 0.39 & $60(26-116)$ & $53(0-115)$ & $\begin{array}{l}\text { Platelet at presentation } \\
10^{9} \text { per } \mathrm{mm}^{3} \text { ) }\end{array}$ \\
\hline 0.3 & 0 & $1(11.1 \%)$ & DSS \\
\hline
\end{tabular}

\section{Discussion}

This series of cases serves to characterize the mortality associated with adult dengue virus infection during an epidemic outbreak in Mukalla city, capital of hadhramoutyemen.

Our study showed that most of fatal cases were male. This correlates with the male to female ratio of hospitalized patients. In terms of prevalence of the disease, a male preponderance has been observed in Saudi Arabia [12,13] and other Asian countries [14], but not in China, Malaysia, America or Bangladesh [15-17]. The exact cause of this difference is unknown, but it could be related to higher exposure to the vector in males during daylight and less in females due to social reasons and to their wearing of hijab. Studies have conflicting evidence on the association of gender with severe dengue or dengue-related death. A meta-analysis and studies in Singapore, Vietnam and Malaysia found that female gender was associated with severe dengue [3]. However, a study in France showed that male gender was associated [17-19] with severe dengue manifestations [20]. It is unclear by which mechanism the age and gender affects the disease manifestation and outcomes [21].

Most of fatal cases were from Mukalla and Fuwwah neighborhoods ( $n=9,47.37 \%)$ and those areas had significant number of cases due to poor sanitary status, presence of stagnated water pools and houses yards. 
Most of death cases in this study were afebrile, which means that the most critical period of the disease is the defervescence of fever, may arise when the signs of circulatory failure and hemorrhagic manifestations, which occurs around the third and fourth days of the disease. This finding was similar to other studies [5,22].

This study found that persistent vomiting, abdominal pain and tenderness, bleeding, hypotension and tachycardia, convulsion, disturbance level of consciousness and severe plasma leakage were associated with dengue related mortality in the overall population like other worldwide studies $[6,7]$ Nausea and/or vomiting should be considered as an early warning sign that can alert the attending health care [21-26] Practitioner to monitor such patients closely [27]. Nausea and vomiting were also found to be associated with dengue shock syndrome in a meta-analysis and other studies $[3,28]$. Bleeding, shock and severe plasma leakage are late manifestations in our study similar to other studies in Pakistan and Singapore $[6,21]$.

Most patients presented with gum bleeding, epistaxis, hemoptysis, hematemesis and vaginal bleeding or mixed sites of bleeding and mostly had mild bleeding episodes did not require any transfusion, except in rare cases in contrast of other study who required transfusions [29].

Most death cases in our study and other studies had low platelet count less than $100,000 /$ cells $/ \mathrm{mm}^{3}[6,27,30,31]$ and low albumin with ascites $[3,17,29]$. Although hematocrit is regarded as a marker for plasma leakage in WHO guidelines, it was not elevated in any death cases in our study. Therefore, like some other studies, hematocrit may not be considered as a sensitive marker of plasma leakage and has low predictive value in our study $[17,26,32]$. This may be because most patients presented with bleeding, and their baseline hematocrit before admission was not known, and even urgent volume replacement can modify this parameter. The important warning laboratory investigations associated with severe dengue and death in this study were elevated liver enzymes, and prolongation of activated partial thromboplastin time with rapid reduction in platelet count like other studies [19,29,31].

Dengue infection usually causes leukopenia [33], Leukocytosis was observed in a significant proportion of our patients $(27.8 \%)$. Leukocytosis may result from secondary infection or reactive due to bleeding. Secondary bacterial infection on presentation has been postulated to be a predictor of death from dengue $[7,23]$.

Severe dengue fever was the most common diagnosis of fatal dengue cases in our study, with shock, hepatic encephalopathy, encephalitis and acute respiratory distress syndrome were the most common causes of deaths like most of the studies [3,5-7,34], somewhat differ from another study where severe bleeding, multi-organ failure and coagulopathy were the primary causes of deaths [17].

Shock has been reported as an important factor for mortality with or without a history of associated blood loss $[5,6]$. It presents in $8(44.4 \%)$ cases, without the association of major bleeding, and was the most important cause of death.
Shock itself is an alarming presentation in patients with dengue virus infection and as an indicator of the severity of disease $[21,23]$. The association between being female gender and risk of shock is not fully understood (since most shocked death cases are females (5 out of 8 cases), but may be explained by gender differences in seeking healthcare as well as physical characteristics $[3,18]$.

Liver damage and neurological complications (encephalitis) were found to be strongly associated with shock in our study, probably due to the sequelae of shock, systemic inflammation, and direct viral invasion into the organs similar to other studies $[3,35,36]$. Fulminant hepatic failure has been reported as the most common cause of encephalopathy in DF [5,35]. The elevation of transaminases was mild to moderate in most cases, but was 10 -fold greater than the normal upper limit for AST and ALT in $16.7 \%$ and $5.4 \%$ of our patients as mentioned in other literature [37] indicating that it is an important warning signs of dengue fever. In contrast to other viral infections which involve the liver, the AST (SGOT) levels were much higher than ALT (SGOT) levels in our study and also other studies [6,37]. The most frequent neurological manifestations were reduced consciousness and convulsions, and encephalitis is one of common cause of this complication in our study like other studies $[35,38]$.

Acute renal failure has a worse prognosis in patients with dengue infection $[17,26,39]$, and it was resulted from shock state or bleeding associated with DF [34] as occurred in two of our patients. A small proportion of patients $(n=3,15.6 \%)$ had co-morbidities like diabetes, asthma and chronic liver disease which was less than other studies $[25,34,40]$ but studies showed that comorbidities were important predictors of mortality in DF $[7,17,21,25,34]$.

Patients who died within 24 hours of presentation and after that, had no significant differences. This implies that more hospital stay has not impact on dengue related deaths in contrast to other studies $[21,23]$. In contrast to other studies $[23,41]$ that reported increase mortality in dengue patients after transfusion of blood products, our study showed no such linkage and there is no evidence of death after platelet transfusions.

A limitation of this study is the fact that RT-PCR or IgM ELISA was not used to confirm the diagnosis due to unavailability. Rapid IgM and IgG and NSI tests was used in nearly all cases, and it has high specificity and sensitivity $[42,43]$ However, a diagnosis of severe dengue was established when criteria were fulfilled, even in the absence of specific diagnostic testing.

\section{Conclusion}

The mortality rate of dengue cases was approximately $4.25 \%$ of all probable cases Death cases was more among male patients, and from Fuwwah and Mukalla city. Alarming signs of dengue-related deaths include nausea, vomiting, abdominal pain and tenderness as early symptoms, and plasma leakage, altered mental status and convulsion as a late signs. Monitoring of the clinical and laboratory parameters that includes leukocytosis, elevated liver enzymes and rapid decline 
in platelets, and also cautious use of antipyretics, fluids, and blood products to provide adequate intravascular volume while avoiding fluid overload are important and can reduce mortality.

Dengue shock was responsible for most of the denguerelated deaths, followed by hepatic encephalopathy and encephalitis. Comorbidities and secondary infections were important factors that can increase the mortality.

\section{Acknowledgements}

We thank the all who help us in data collection and statistical analysis of this study particularly members of medical and statistical departments in Ibn-Sina general hospital authority.

\section{References}

1. Bhatt S, Gething PW, Brady OJ, Messina JP, Farlow AW, et al. (2013) The global distribution and burden of dengue. Nature 496: 504-507.

2. World Health Organization (2011) Comprehensive guidelines forprevention and control of dengue and dengue hemorrhagic fever. New Delhi, India 14: 16.

3. Huy NT, Van GT, Thuy DHD, Kikuchi M, Hien TT, et al. (2013) Factors associated with dengue shock syndrome: a systematic review and meta-analysis. PLoS Negl Trop Dis 7: e2412.

4. Ranjit S, Kissoon N (2011) Dengue hemorrhagic fever and shock syndromes. Pediatr Crit Care Med 12: 90-100.

5. Montenegro D, Lacerda HR, Lira TM, de Oliveira DSC, de Lima AAF, et al. (2006) Clinical and epidemiological aspects of the dengue epidemic in Recife, PE, 2002. Rev Soc Br as Med Trop 39: 9-13.

6. Almas A, Parkash O, Akhter J (2010) Clinical factors associated with mortality in dengue infection at a tertiary care center. Southeast Asian J Trop Med Public Health 41: 333-340.

7. Lahiri M, Fisher D, Tambyah PA (2008) Dengue mortality: reassessing the risks in transition countries. Trans $\mathrm{R}$ Soc Trop Med Hyg 102: 1011-1016.

8. Gubler DJ (2011) Dengue, urbanization and globalization: the unholy trinity of the 21st century. Trop Med Health 39: S3-S11.

9. Muhandis AN, Hunter PR (2011) The value of educational messages embedded in a community-based approach to combat dengue fever: a systematic review and meta regression analysis. PLoS Negl Trop Dis 5: e1278.

10. Ghouth ASB, Amarasinghe A, Letson GW (2012) Dengue outbreak in Hadramout, Yemen, 2010: an epidemiological perspective. Am J Trop Med Hyg 86: 1072-1076.

11. Madani TA, Abuelzein ETM, Bar HM, Azhar El, Kao M, et al. (2013) Outbreak of viral hemorrhagic fever caused by dengue virus type 3 in Al-Mukalla, Yemen. BMC Infect Dis 13: 1.

12. Shahina W, Nassara A, Kalkattawia M, Bokharia H (2009) Dengue fever in a tertiary hospital in Makkah, Saudi Arabia. Dengue Bulletin. 33: 34-43.

13. Ayyub M, Khazindar AM, Lubbad EH, Barlas S, Alfi AY, et al. (2006) Characteristics of dengue fever in a large public hospital, Jeddah, Saudi Arabia. J Ayub Med Coll Abbottabad 18: 9-13.
14. Anker M, Arima $Y$ (2011) Male-female differences in the number of reported incident dengue fever cases in six Asian countries. West Pac Surveill Response J 2: 17-23.

15. Ying RS, Tang XP, Zhang FC, Cai WP, Chen YQ, et al. (2007) Clinical characteristics of the patients with dengue fever seen from 2002 to 2006 in Guangzhou. J Exp Clin Virol 21: 123-125.

16. Guha SD, Schimmer B (2005) Dengue fever: new paradigms for a changing epidemiology. Emerg Themes Epidemiol 2: 1.

17. Sam SS, Omar SFS, Teoh BT, Abd JJ, Abu Bakar S (2013) Review of dengue hemorrhagic fever fatal cases seen among adults: a retrospective study. PLoS Negl Trop Dis 7: e2194.

18. Anders KL, Nguyet NM, Chau NVV, Hung NT, Thuy TT, et al. (2011) Epidemiological factors associated with dengue shock syndrome and mortality in hospitalized dengue patients in Ho Chi Minh City, Vietnam. Am J Trop Med Hyg 84: 127-134.

19. Yew YW, Ye T, Ang LW, Ng LC, Yap G, et al. (2009) Seroepidemiology of dengue virus infection among adults in Singapore. Ann Acad Med Singap 38: 667-675.

20. Thomas L, Brouste Y, Najioullah F, Hochedez P, Hatchuel Y, et al. (2010) Predictors of severe manifestations in a cohort of adult dengue patients. J Clin Virol 48: 96-99.

21. Leo YS, Thein TL, Fisher DA, Low JG, Oh HM, et al. (2011) Confirmed adult dengue deaths in Singapore: 5-year multicenter retrospective study. BMC Infect Dis 11: 1.

22. Ong A, Sandar M, Chen MI, Sin LY (2007) Fatal dengue hemorrhagic fever in adults during a dengue epidemic in Singapore. Int J Infect Dis 11: 263-267.

23. Assir MZK, Ahmad HI, Masood MA, Kamran U, Yusuf NW (2014) Deaths due to dengue fever at a tertiary care hospital in Lahore, Pakistan. Scand JInfect Dis 46: 303-309.

24. Liew SM, Khoo EM, Ho BK, Lee YK, Omar M, et al. (2016) Dengue in Malaysia: Factors Associated with Dengue Mortality from a National Registry. PloS One 11: e0157631.

25. Guzmán MG, Alvarez M, Rodriguez R, Rosario D, Vázquez S, et al. (1999) Fatal dengue hemorrhagic fever in Cuba, 1997. Int J Infect Dis 3: 130-135.

26. Rigau PJG, Laufer MK (2006) Dengue-related deaths in Puerto Rico, 1992-1996: diagnosis and clinical alarm signals. Clin Infect Dis 42: 1241-1246.

27. Liew SM, Khoo EM, Ho BK, Lee YK, Omar M, et al. (2016) Dengue in Malaysia: Factors Associated with Dengue Mortality from a National Registry. PloS One 11: e0157631.

28. Cheah WK, Ng KS, Marzilawati AR, Lum LC (2014) A review of dengue research in malaysia. Med J Malaysia 69: 59-67.

29. Ahmed S, Mohammad WW, Hamid F, Akhter A, Afzal RK, et al. (2013) The 2011 dengue haemorrhagic fever outbreak in Lahore-an account of clinical parameters and pattern of haemorrhagic complications. J Coll Physicians Surg Pak 23: 463-467.

30. Moraes GH, Fátima DE, Duarte EC (2013) Determinants of mortality from severe dengue in Brazil: a population-based casecontrol study. Am J Trop Med Hyg 88: 670-676.

31. Chua MN, Molanida R, Guzman DM, Laberiza F (1992) Prothrombin time and partial thromboplastin time as a predictor of bleeding in patients with dengue hemorrhagic fever. Southeast Asian J Trop Med Public Health 24: 141-143. 
32. Méndez Á, González G (2003) Dengue hemorrágico en niños: diez años de experiencia clínica. Biomédica 23: 180-93.

33. Ahmed S, Arif F, Yahya Y, Rehman A, Abbas K, et al. (2008) Dengue fever outbreak in Karachi 2006-a study of profile and outcome of children under 15 years of age. JPMA J Pak Med Assoc 58: 4.

34. Bhaskar ME, Moorthy S, Kumar NS, Arthur P (2010) Dengue haemorrhagic fever among adults-an observational study in Chennai, South India. Indian J Med Res 132: 738.

35. Murthy JMK (2010) Neurological complications of dengue infection. Neurol India 58: 581.

36. Assir MZK, Jawa A, Ahmed HI (2012) Expanded dengue syndrome: subacute thyroiditis and intracerebral hemorrhage. BMC Infect Dis 12: 240.

37. Kuo CH, Tai D, Chang CS, Lan CK, Chiou SS, et al. (1992) Liver biochemical tests and dengue fever. Am J Trop Med Hyg 47: 265-270.

38. Solomon T, Dung NM, Vaughn DW, Kneen R, Raengsakulrach B, et al. (2000) Neurological manifestations of dengue infection. The Lancet 355: 1053-1059.
39. Kuo MC, Lu PL, Chang JM, Lin MY, Tsai JJ, et al. (2008) Impact of renal failure on the outcome of dengue viral infection. Clin J Am Soc Nephrol 3: 1350-1356.

40. Lee K, Liu JW, Yang KD (2008) Clinical and laboratory characteristics and risk factors for fatality in elderly patients with dengue hemorrhagic fever. Am J Trop Med Hyg 79: 149-153.

41. Lum LCS, Abdel LA, Goh AYT, Chan PWK, Lam SK (2003) Preventive transfusion in dengue shock syndrome-is it necessary. J Pediatr 143: 682-684.

42. Fry SR, Meyer M, Semple MG, Simmons CP, Sekaran SD, et al. (2011) The diagnostic sensitivity of dengue rapid test assays is significantly enhanced by using a combined antigen and antibody testing approach. PLoS Negl Trop Dis 5: e1199.

43. Wang SM, Sekaran SD (2010) Early diagnosis of Dengue infection using a commercial Dengue Duo rapid test kit for the detection of NS1, IGM, and IGG. Am J Trop Med Hyg 83: 690-695. 